\title{
Clinical Pearls in Anesthesia for Xeroderma Pigmentosum: A Case Report
}

\author{
S.B. Shah*, U. Hariharan, B.K. Naithani and A.K. Bhargava \\ Rajiv Gandhi Cancer Institute and Research Centre; Sec-5; Rohini, Delhi-110085, India
}

\begin{abstract}
Xeroderma Pigmentosum (XP) is a rare autosomal recessive (AR) disease characterized by hypersensitivity of the skin to ultra violet (UV) radiation, resulting in a high frequency of UV induced skin tumors and progressive neurological complications at an early age. Through the following case report we emphasize that perioperative management of xeroderma patients entails meticulous evaluation for neurological abnormalities, shielding the skin from OT (operation theatre) lights by using protective clothing, sunscreen and UV blocking film as well as avoidance of genotoxic drugs like volatile anaesthetics and paracetamol. One must be prepared for the possibility of difficult mask ventilation (we used a mask one size larger), difficult intubation and prolonged effect of muscle relaxants (as in our case) due to skin atrophy, neoplasia, joint contracture and neuronal dysfunction.
\end{abstract}

Keywords: Basal cell carcinoma, genotoxic drugs, muscle relaxants, ultraviolet light, volatile anaesthetics, xeroderma pigmentosum.

\section{INTRODUCTION}

The prevalence of Xeroderma Pigmentosa (XP) is 1:250,000 globally. Here, the ability to repair damage caused by ultraviolet (UV) rays is deficient due to Nucleotide Excision Repair (NER) damage $[1,2]$. XP patients (colloquially called "children of the night") have a 1000-fold increased risk of developing neoplasias on sun exposed areas. Multiple basal cell carcinomas are frequent. Metastatic malignant melanoma and squamous cell carcinoma are common causes of death $[3,4]$. We present a patient of xeroderma pigmentosa who was posted for basal cell neoplasm (BCC) excision of the nose. Initially she presented for excision of $\mathrm{BCC}$ on right ala of nose and six months later, for excision of $\mathrm{BCC}$ on her left nostril.

\section{CASE REPORT}

A 12 year old, $27 \mathrm{Kg}$ female, presented with mottled blackish pigmentation over sun exposed areas of her skin. She was diagnosed with a growth (size $6 \mathrm{~cm} \times 4 \mathrm{~cm} \times 3 \mathrm{~cm}$ ) protruding out of the right nasal cavity since the past one month, accompanied by nasal bleeding. There was intense lacrymation from her eyes and the conjunctiva was chemosed. The family history was positive, with her younger sister also suffering from xeroderma pigmentosa.

A detailed preanaesthetic evaluation was done as per routine, with special attention to protecting her exposed parts. In the ward, an IV access was obtained gently. A nonabrasive, hypoallergenic UV blocking sunscreen (Sun Protection Factor: 40) was applied on all the exposed areas of her skin followed by draping with protective clothing. Intravenous $0.5 \mathrm{mg}$ midazolam was injected as premedication. In the OT, the patient was preoxygenated with $100 \%$ oxygen using a face mask one size larger than what would normally

*Address correspondence to this author at the Rajiv Gandhi Cancer Institute and Research Centre; sec-5; Rohini, Delhi-110085, India; Tel: 9891769779; E-mail: drshagun_2010@rediffmail.com fit her face (to accommodate the tumor) and a sterile gauze with paraffin tulle on one side was placed on her lesion prior to masking to avoid trauma. Anaesthesia was induced using fentanyl $40 \mu \mathrm{g}$ IV followed by propofol $55 \mathrm{mg}$ IV. Succinylcholine was used in a dose of 40mg IV and a six mm ID endotracheal tube (ETT) was orally inserted into the trachea and ETT position confirmed by auscultation and capnography. Antibiotic eye ointment was applied before patching and padding her eyes. Her face, neck and extremities were covered with cotton before switching the OT lights on. Total intravenous anaesthesia (TIVA) was utilized using a propofol infusion $(4 \mathrm{mg} / \mathrm{ml}$ at $10-15 \mathrm{ml} /$ hour$)$ and two intermittent fentanyl boluses of $5 \mu \mathrm{g}$ each. Besides routine monitoring, bispectral index (BIS) and neuromuscular monitoring were used. The effect of succinylcholine lasted 24 minutes which also happened to be the surgical time. Extubation was uneventful. Postoperative analgesia with IV diclofenac and tramadol both $25 \mathrm{mg} 8$ hourly was given.

The same patient presented six months later, with an ulcerated left nostril growth. This time again, BIS- guided TIVA with propofol and fentanyl for anaesthesia was utilised (Fig. 1). As the duration of action of succinylcholine was prolonged in the previous instance, this time two smaller doses of succinylcholine (25mg I.V) 10 minutes apart was administered. The rest of the perioperative course was uneventful. The same precautions and monitoring were utilized in this surgery as was done in the first time. Postoperatively also, special care was taken to protect and cover her exposed areas.

\section{DISCUSSION}

Xeroderma Pigmentosum (XP) is a rare genetic disorder affecting the skin and the nervous system. At birth, the skin appears normal. Onsetting at around 6 months, XP progresses to stage-1 with sun exposed areas showing erythema and freckling. Continuous sun- exposure leads to stage-2 XP, presenting with poikiloderma, solar lentigines, skin atrophy, 


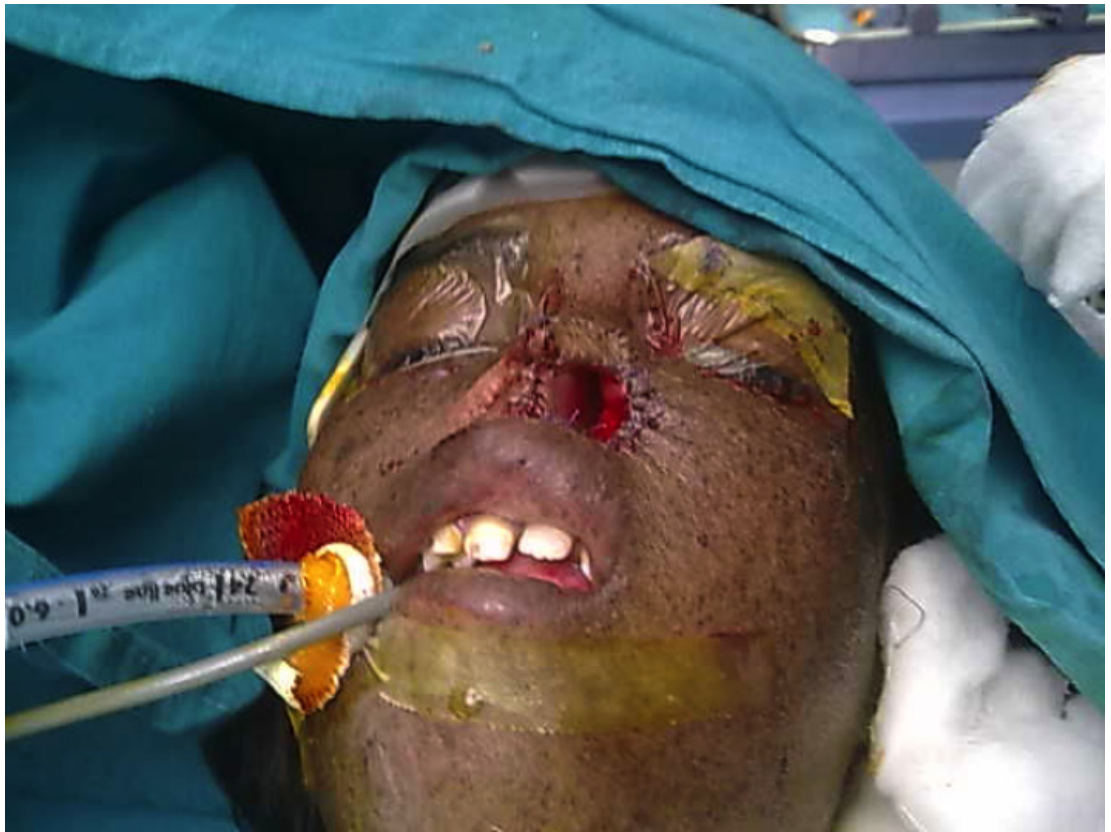

Fig. (1). Intra operative image of xeroderma pigmentosa patient.

telangiectasias, patches of hypopigmentation and hyperpigmentation. Stage-3 involves development of actinic keratoses and skin cancer occurring anywhere between 4-5 years of age to adolescence $[3,4]$.

Neurological abnormalities include loss of highfrequency hearing (commonest), poor co-ordination, hyporeflexia, progressive mental retardation, seizures and spasticity, [5] all of which may worsen with the use of volatile anaesthetic agents $[1,2,6]$. Ocular symptoms include photophobia, conjunctivitis, loss of vision, irritation, blepharitis, keratitis and ocular neoplasia.

Hypersensitivity to environmental mutagens (cigarette smoke and alcohol) exists. Perioperative management entails meticulous evaluation of airway, neurological abnormalities, shielding the skin from OT lights by using protective clothing, ultraviolet (UV) blocking film $[7,8]$ and avoidance of drugs like paracetamol, halothane, isoflurane and sevoflurane which are known to derange Nucleotide Excision Repair (NER) $[1,2,9]$. Comet assay [10, 11] (alkaline single cell gel electrophoresis) demonstrates peripheral blood lymphocyte DNA damage at $60 \mathrm{mins}$ and at $120 \mathrm{mins}$ of anaesthesia with 1 to $1.5 \%$ halothane, isoflurane and sevoflurane. The anesthetics-induced DNA strand breaks as well as alkali-labile sites are measured as total comet length (i.e., increase of a DNA migration). Volatile anaesthetics increase DNA migration in a dose-dependent manner. Halothane increases DNA migration to a higher extent than isoflurane. The comet assay detects DNA strand breaks induced directly by genotoxic agents as well as DNA degradation due to cell death. Increase of DNA migration induced in PBL by isoflurane at $1 \mathrm{mM}$ and by halothane at $0.1 \mathrm{mM}$ is caused by their genotoxic action. This is repaired by the $5^{\text {th }}$ post-operative day in normal patients, but in XP patients, it leads to progression of neurological symptoms [10]. Therefore we preferred TIVA (total intravenous anaesthesia) to volatile anaesthetic usage. There is also increased sensitivity to synergistic effects of benzodiazepines and opioids due to immature brain development. Hence, we used lower end of the dose range for midazolam, morphine and fentanyl [6].

All preparations for difficult airway were done preoperatively. Possibility of difficult masking, difficult intubation and prolonged effect of muscle relaxation due to skin atrophy, neoplasia, joint contracture and neuronal dysfunction exists. Hence, we used a short- acting neuromuscular blocker (succinylcholine) to facilitate tracheal intubation. Succinylcholine effect was prolonged in the first surgery, probably due to deficiency in pseudo cholinesterase levels and hence, we reduced the dose during second surgery.

\section{CONCLUSION}

Eliciting a family history, detailed neurological evaluation, prior counselling regarding strict avoidance of sun, cigarette smoking and alcohol to delay disease progression and stressing the importance of sun- protective clothing, eye gear, sunblock creams cannot be over-emphasized. We advocate avoidance of genotoxic drugs like halothane, isoflurane, sevoflurane and paracetamol due to derangement in NER. We recommend opting for BIS guided TIVA for general anaesthesia, cautious use of opioids and benzodiazepines and utilizing shorter acting neuromuscular blocking agents under strict PNS (peripheral nerve stimulator) guidance. Gentle handling of the patient during all manoeuvres and special care of their fragile skin is very important.

\section{CONFLICT OF INTEREST}

The authors confirm that this article content has no conflict of interest.

\section{ACKNOWLEDGEMENTS}

Declared none. 


\section{REFERENCES}

[1] Miyazaki R, Nagata T, Kai T, Takahashi S. Anaesthesia for a patient with xeroderma pigmentosum. Masui 2007; 56(4): 439-41.

[2] Masuda Y, Imaizumi H, Okanuma M, Narimatsu E, Asai Y, Namiki A. Anaesthesia for a patient with xeroderma pigmentosum Masui 2002; 51(2): 169-71.

[3] Lichon V. Xeroderma Pigmentosum: beyond skin cancer. J Drugs Dermatol 2007; 6: 281-8.

[4] Kraemer KH, Patronas NJ, Schiffmann R, Brooks BP, Tamura D, DiGiovanna JJ. Xeroderma Pigmentosum, Trichothiodystrophy and Cockrayne syndrome: a complex genotype-phenotype relationship. Neuroscience 2007; 145: 1388-96.

[5] Anttinen A, Koulu L, Nikoskelainen E, et al. Neurological symptoms and natural course of xeroderma pigmentosum. Brain 2008; 131(8): 1979-89.

[6] Shrestha GS, Shah RP, Amatya AG, Shrestha N. Anaesthetic management of patients with Xeroderma pigmentosum. A series of three cases. Nepal Med Coll J 2011; 13(3): 231-2.
[7] Soen M, Kagawa T, Uokawa R, Suzuki T. Anaesthetic management of a patient with xeroderma pigmentosum. Masui 2006; 55(2): 215-7.

[8] Tatsuo O, Takashi I. Anaesthesia for a Patient with Xeroderma Pigmentosum. J Clin Anaesth 2005; 29(5): 909-10.

[9] T. Brunner, M. Jöhr. Anesthetic management of a child with xeroderma pigmentosum. Pediatric Anaesthesia 2004; 14(8): 621712 .

[10] Karabiyik L, Sardas S, Polat U, KocabaS NA, Karakaya AE. Comparison of genotoxicity of sevoflurane and isoflurane in human lymphocytes studied in vivo using the comet assay. Mutat Res 2001; 492(1): 99-107.

[11] Jaloszyński P, Kujawski M, Wasowicz M, Szulc R, Szyfter K. Genotoxicity of inhalation anaesthetics halothane and isoflurane in human lymphocytes studied in vitro using the comet assay. Mutat Res 1999; 439(2): 199-206.

(C) Shah et al.; Licensee Bentham Open.

This is an open access article licensed under the terms of the (https://creativecommons.org/licenses/by/4.0/legalcode), which permits unrestricted, noncommercial use, distribution and reproduction in any medium, provided the work is properly cited. 